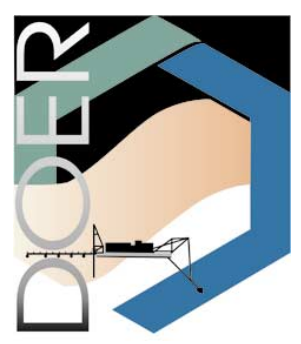

\title{
Simulating Underflow Spreading from a Shallow-Water Pipeline Disposal
}

PURPOSE: A computational model for simulating a pipeline discharge underflow in shallow water is presented herein. Information on extent of initial spreading from a dredge pipeline discharge can be important for managing and sizing disposal areas and evaluating possible water quality impacts. For example, results from this model will be used by the SSFATE model to compute entrainment of disposed material into the overlying water column and subsequent plume dispersion by currents. Other far field models have been used to assess the long-term fate of material eroded from disposal mounds, requiring disposal footprint area specification. The purpose of the model presented here is to predict the extent of initial spreading or footprint, concentration, deposition thickness, etc. for a pipeline discharge. The STFATE model makes corresponding predictions for barge-disposed dredged material.

BACKGROUND: Field observations indicate that most pipeline-discharged dredged material spreads as a dense underflow under the effect of gravity. Regardless of the discharge configuration, the behavior of the vast majority of particles between the discharge point and the point of deposition is governed by the spreading dynamics of a particle laden, dense underflow - as discussed in Teeter (2000).

A hydraulic dredge discharge into shallow water can have a variety of end-or-pipeline configurations which affect the initial dilution immediately adjacent to the end of the pipe or diffuser, and affect the formation of the underflow. In shallow water, a discharge jet can reach the bottom with appreciable momentum and little dilution. This may result in a scour hole as shown in Figure 1 and appreciable energy dissipation at the point of bed impact. Another situation occurs when a horizontal discharge pipe has a diameter equal to an appreciable fraction of the receiving water depth. In this case a turbulent surface flow is created which, after some initial entrainment and spreading, plunges to form an underflow in slightly deeper water as shown in Figure 2. This was observed during February 2000 in Laguna Madre, TX, as shown in Figure 3.

Near field processes such as jet entrainment and convection terminate in a flow transition where an underflow is formed. Transition conditions include the initial dilution that has occurred in the near field after the discharge and before the underflow transition, the underflow thickness or height, breadth, and Richardson number. The pipeline underflow model does not include near field processes directly. These are assumed to be known or can be calculated using a separate near field model such as CD-CORMIX. ${ }^{1}$

The following features are deemed important and were included in the model formulation:

- Deposition of sediment particles according to concentration dependent settling rates and shear stress thresholds related to sediment characteristics.

1 Doneker, R. L., Jirka, G. H., and Nash, J. D. (1995). "CD-CORMIX model for continuous dredge disposal mixing zone analysis,” EPA Contract No. 68-C3-0374, Draft final report, Tetra Tech, Inc. Fairfax, VA. 
ERDC TN-DOER-N11

April 2001

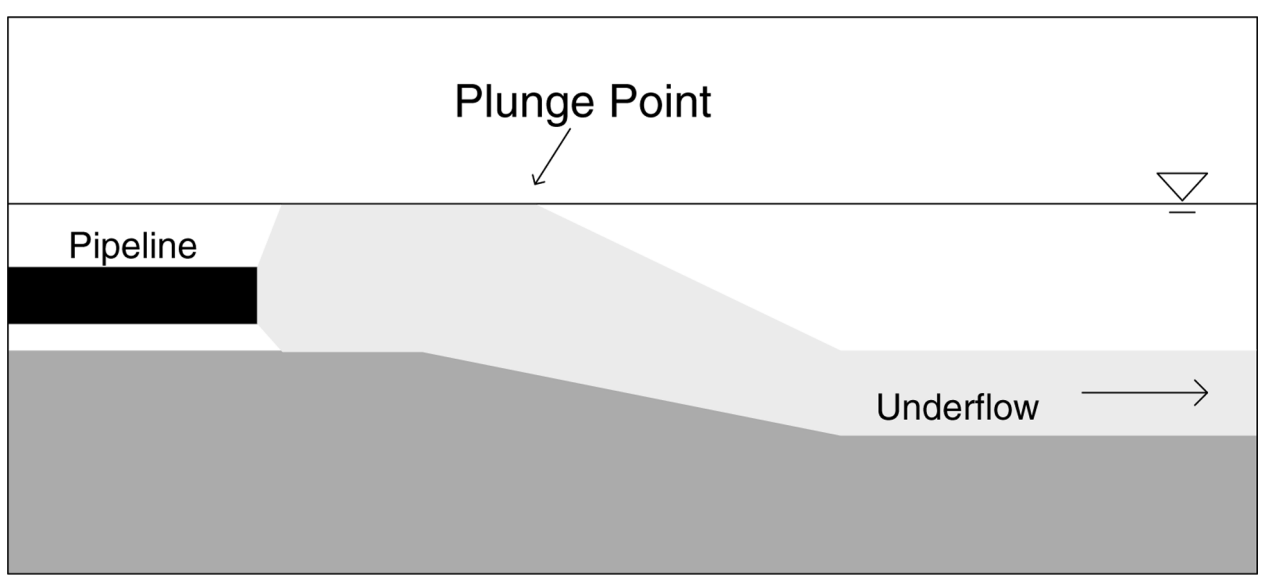

Figure 1. Schematic of a vertically-downward pipeline discharge and the resulting transition to an underflow

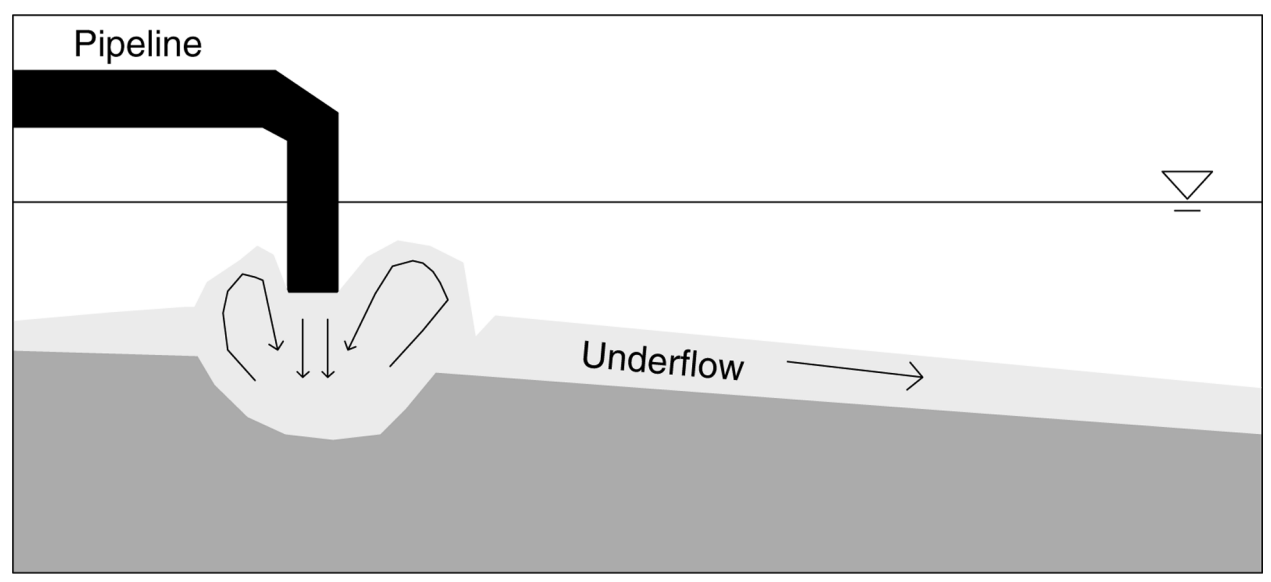

Figure 2. Schematic of a shallow horizontal pipeline discharge, turbulent surface flow, and transition to an underflow at a plunge point

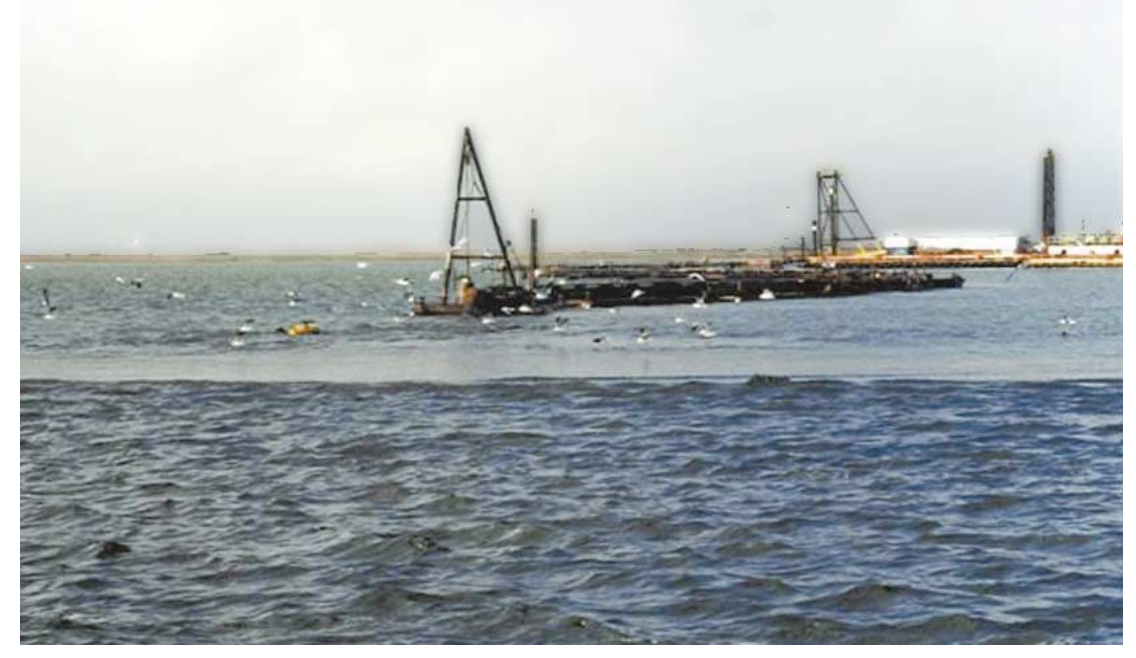

Figure 3. Pipeline discharge into about $0.5-\mathrm{m}$ water depth and the resulting turbulent surface flow 
- Entrainment of overlying water into the underflow according to the local Richardson number of the underflow.

- Appropriate flow properties of the underflow suspension.

- Lateral spreading of the underflow.

- Variable bottom slope.

MODEL DESCRIPTION: The underflow model computes sediment flux, total flow or discharge, breadth, and height along the length of the underflow. These state variables are calculated by numerically integrating a set of governing equations downslope in the direction of the underflow. The bed is assumed to be planar with an arbitrary slope which is allowed to vary in the downslope direction. The underflow is considered quasi-steady or steady over a short duration of time. Thus, time derivatives are ignored in the governing equations. However, time of travel to every discrete location along the underflow trajectory can be calculated by integrating the underflow velocity. After the first full numerical integration sweep from the transition (beginning) to the end of the underflow, subsequent sweeps are made in discrete time intervals and include updated bed elevations based on the cumulative depositional thickness from preceding sweeps. Sweeps are made at intervals of about 1800-second so that deposit thickness changes per sweep are small. Thus, the model makes many sweeps over the underflow domain and duration of the discharge to update deposit thickness del_bed and bed slope. Other variables are calculated from the basic state variables and used to solve auxiliary equations for entrainment, bed friction coefficient, depositional flux, yield stress, viscosity, and underflow arresting. These variables include underflow concentration, velocity, deposit thickness, Reynolds and Richardson numbers.

Underflow Transition. The underflow transition forms the initial conditions for the underflow. Dredge pipeline underflows are turbulent at their origins, and most often have Richardson numbers $R_{i}$ of about unity (Bonnecaze and Lister 1999). For example, the critical $R_{i}$ for a plunging underflow described earlier is about 1 (Fang and Stefan 1998). The Richardson number is defined here to include the bed slope:

$$
R_{i}=\frac{g \Delta \rho h \cos \theta}{\rho U^{2}}
$$

where $g$ is the acceleration of gravity, $\Delta \rho$ is the density difference between the underflow and the overlying ambient suspension (i.e., $\left.\rho-\rho_{1}\right), \rho$ is the depth-average underflow density $\left(\rho=\rho_{1}+\Delta \rho\right)$, $h$ is the thickness normal to the plane of the bed, $\theta$ is the angle of the bed from the horizontal, and $U$ is the depth-average velocity. The excess density $\Delta \rho$ is related to the underflow concentration $C: \Delta \rho=s^{\prime} C$ where $s^{\prime}=\left(\rho_{\mathrm{s}}-\rho_{1}\right) / \rho_{s}$ and $\rho_{s}=$ the sediment particle density. Some definitions are shown schematically in Figure 4 . 


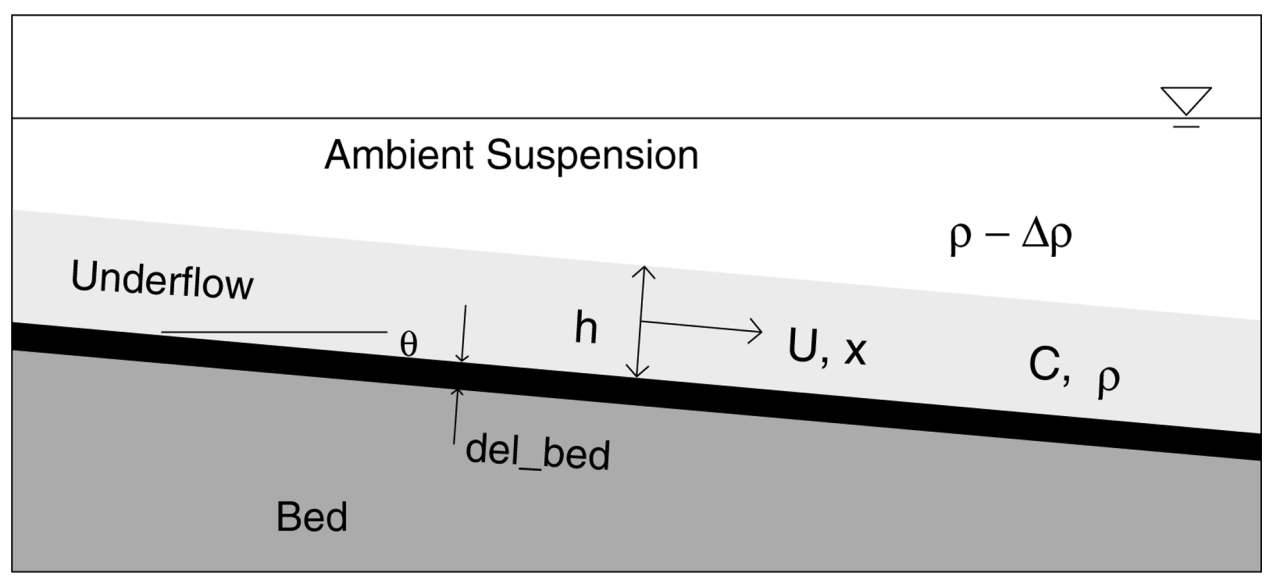

Figure 4. Definition of some model variables

In addition to the discharge and discharge concentration $\left(Q_{d}\right.$ and $\left.C_{i}\right)$, the model requires specification of the initial dilution $S a$, initial breadth $B_{o}$, and initial $R_{i}$. From this information, the initial height $h_{o}$ can be estimated by:

$$
h_{o}=\left(\frac{Q_{o}}{B_{o}}\right)^{2 / 3}\left(\frac{\rho_{o} R_{i o}}{g \Delta \rho_{o}}\right)^{1 / 3}
$$

where the subscript $o$ refers to values at the underflow transition, $Q_{o}=S a Q_{d}$, and $C_{o}=C_{i} / S a$.

Layer-Averaged Model Equations. The governing equations are based on mass and momentum conservation. The cross-section integral momentum balance for a quasi-steady density-driven underflow is:

$$
\frac{d\left(\rho U^{2} A\right)}{d x}=-\tau_{b}-\tau_{t}-\frac{d}{d x}(0.5 g \Delta \rho A \cos \theta)+g \Delta \rho A \sin \theta
$$

where $x=$ downslope distance; $A=$ underflow cross-sectional area; $\tau_{\mathrm{b}}=$ bed shear stress; and $\tau_{t}=$ shear stress at the top of the underflow. The conservation of sediment mass in the flow is:

$$
\frac{d(C Q)}{d x}=-B S
$$

where

$$
S=P W_{s} C \quad \text { for } \quad \tau_{b}<\tau_{c d}
$$

and

$$
S=0.0 \quad \text { for } \quad \tau_{b} \geq \tau_{c d}
$$


$S=$ the depositional flux, $Q=$ underflow discharge, the probability of deposition $P=1-\tau_{b} / \tau_{c d}$, $\tau_{c d}$ is the threshold shear stress for deposition, and $B=$ underflow breadth. Deposition ceases at bed shear stresses greater than $\tau_{c d}$. The conservation of underflow volume is:

$$
\frac{d Q}{d x}=E_{w} U B-S B / C_{S}
$$

where $E_{w}$ is the entrainment coefficient, and $C_{S}$ is the solids content of the underflow deposit. The first term on the right-hand side is increase in discharge by entrainment, and the second term is discharge decrease by the deposition of solid and liquid volume that form the deposited bed. Equations 3-5 can be manipulated to give the thickness change along $x$, as modified from Findikakis and Law (1998):

$$
\frac{d h}{d x}=\left[1.43 C_{d}-R_{i} \tan \theta+\frac{2}{B U} \frac{d Q}{d x}+\left(\frac{R_{i}}{2}+\frac{\Delta \rho}{\rho}\right)\left(\frac{1}{C} \frac{d(C Q)}{d x}-\frac{h}{Q} \frac{d Q}{d x}\right)\right] /\left(1-R_{i}\right)
$$

where $C_{d}=$ the drag coefficient, and the factor 1.43 relates the bed shear stress to the total of the bed and the top shear stresses (Findikakis and Law 1998). Equation 6 is not valid for the critical condition $R_{i}=1$. This condition is avoided by adjusting the flow thickness (and hence $R_{i}$ ) as $R_{i}$ approaches unity using a procedure similar to Garcia (1994).

The governing Equations 4-6 and auxiliary equations described in the subsections that follow are integrated, starting with the initial condition described in the last section, using a fourth order numerical scheme to calculate $Q, C Q, B$, and $h$ along the downslope trajectory of the underflow.

Entrainment. Several relationships between entrainment coefficient $E_{w}$ and $R_{i}$ have been proposed and that of Kranenburg and Winterwerp (1997) was used here where:

$$
E_{w}=\frac{5.5 \times 10^{-3}}{3.6 R_{i}-1+\sqrt{\left(3.6 R_{i}-1\right)^{2}+0.15}}
$$

At low $R_{i}$ the entrainment coefficient reaches a maximum value of about 0.08 , while at $R_{i}=1$, $E_{w}$ is about 0.001 .

Settling. When suspension concentration exceed about $1 \mathrm{~kg} / \mathrm{m}^{3}$, interaggregate distances become small and hinder settling can occur. A general hindered settling function is used in the model to simulate this process:

$$
W_{s}=w s 1(1-b 2 C)^{b 1}
$$

where $w s 1$ is a reference, maximum settling rate, and the coefficient symbols correspond to model input as described in the next section. The parameter $b 2$ is the inverse of the fully-settled 
concentration. A typical $b 1$ value is about 5 for muds and settling velocity usually decreases rapidly at high suspension concentration.

Lateral Spreading. Bonnecaze and Lister (1999) studied the cross slope extent of particle-driven density currents by scaling analysis and two-dimensional numerical solutions. Based on their results, and with a substitution of $R_{i} / C_{d}$ for $\cos \theta / \sin \theta$, the spreading rate used in the Pipeline Discharge FATE (PDFATE) model is:

$$
\frac{d B}{d x}=1.7\left(\frac{E_{w} R_{i}}{C_{d}}\right)^{1 / 2}
$$

Suspension Flow and Frictional Properties. As described in Teeter (2000), the flow properties, or rheology, of mud suspensions is complex. In the model, the suspension is assumed to have a yield stress similar to a Bingham plastic. The yield stress $\tau_{y}$, high-shear viscosity $\mu_{h}$, and low-shear viscosity $\mu_{1}$ are assumed to be dependent of the concentration of the suspension according to the following power laws:

$$
\begin{aligned}
& \tau_{y}=t u y 1\left(\frac{C}{\rho_{s}}\right)^{t u y 2} \\
& \mu_{h}=\mu_{w}\left[1+m u 1\left(\frac{C}{\rho_{s}}\right)^{m u 2}\right] \\
& \mu_{1}=\mu_{w}\left[1+m u 3\left(\frac{C}{\rho_{s}}\right)^{m u 4}\right]
\end{aligned}
$$

where $\mu_{w} \equiv 0.001 \mathrm{~Pa} / \mathrm{sec}$, the dynamic viscosity of water, and $\rho_{s}$ is the particle or solids density, usually about $2650 \mathrm{~kg} / \mathrm{m}^{3}$, and the parameter symbols are keyed to the model input to be described in the next section. The underflow is assumed to initiate as a turbulent flow with high shear rate. With distance downslope, the near-bed shear rate is estimated using the velocity profile presented by Van Kessel and Kranenburg (1996). The high-shear viscosity continues to be used up to the point where the shear rate drops to 5 per sec or less, after which the low-shear viscosity is used. The low shear viscosity is much greater than the high-shear viscosity. The drag coefficient is estimated as presented by Van Kessel and Kranenburg (1996):

$$
C_{d}=\frac{12}{R_{\mu}}+\frac{\tau_{y}}{\rho U^{2}}
$$

where $R_{\mu}=4 \rho \mathrm{Q} / \mathrm{B} \mu$ is the viscous contribution to the Reynolds number, and the second term on the right side of Equation 13 is the yield stress contribution $R_{\tau}$. By switching between high and low 
shear viscosities, a simple two-level approximation is made for the shear-thinning behavior of mud, which was described by Equation 2 of Teeter (2000).

Laminar Flow. Drag coefficients increase sharply at low Reynolds number. In addition, when $R<2000$, the model switches modes for transport and the model assumes that the depositing underflow collapses vertically (much as observed in a quiescent column settling experiment) without changes in concentration. In this case:

$$
\frac{d Q}{d x}=\frac{1}{C} \frac{d(C Q)}{d x}
$$

and thus the underflow concentration does not decrease with deposition as is the case under turbulent flow conditions. This model feature was added based on field observations of underflow concentrations in Laguna Madre, TX.

MODEL INPUT AND EXAMPLE APPLICATION: Two model versions have been coded. The Pipeline-Discharge Underflow model PDFATEs uses a single grain class while PDFATEm considers multiple grain classes. The PDFATEm model will be used for input to SSFATE and for more detailed underflow analyses, while the PDFATEs model is more appropriate for screening purposes or when detailed data are lacking. The input for PDFATEs is described in this section.

An input file specifying site specific information is developed and used to operate the PDFATEs model. The input file is divided into groups of input parameters: discharge conditions, transition conditions, ambient suspension characteristics, underflow sediment conditions, run control, and depths. Provisions for an ambient suspension and water column flow have been made in the model but are not yet implemented. Depth input is separated into its own group because this input can be lengthy. The following tables describe the PDFATEs input groups for an observed pipeline discharge in Laguna Madre, TX. Many of the sediment characteristics were assumed from reported values at other sites.

\begin{tabular}{|l|l|l|l||}
\hline \multicolumn{4}{|l||}{ Table 1. Discharge Group of Input Parameters } \\
\hline $\begin{array}{l}\text { PDFATEs } \\
\text { Symbol }\end{array}$ & Description & Typical Value & Unit \\
\hline \hline Lat_dischg & Latitude of discharge & 26.7349 & degree \\
\hline Long_dischg & Longitude of discharge & 97.2841 & degree \\
\hline O_dischrg & Orientation of discharge from north & 105. & degree \\
\hline Q_dischg & Pipeline discharge rate & 0.5 & $\mathrm{~m}^{3} / \mathrm{sec}$ \\
\hline C_dischg & Sediment concentration in pipeline & 125. & $\mathrm{~kg} / \mathrm{m}^{3}$ \\
\hline
\end{tabular}




\begin{tabular}{|l|l|l|l||}
\hline \multicolumn{4}{|l||}{ Table 2. Transition Condition Group of Input Parameters } \\
\hline $\begin{array}{l}\text { PDFATEs } \\
\text { Symbol }\end{array}$ & Description & Typical Value & Unit \\
\hline \hline Sa & Dilution prior to underflow & 4. & 0 \\
\hline B_o & Width at the point of underflow formation & 10. & $\mathrm{~m}$ \\
\hline Ri_o & $R_{i}$ at the point of underflow formation & 1.2 & 0 \\
\hline rho_1 & Ambient fluid density & 1026. & $\mathrm{~kg} / \mathrm{m}^{3}$ \\
\hline \hline
\end{tabular}

\begin{tabular}{|l|l|l|l||}
\hline \multicolumn{4}{|l|}{ Table 3. Ambient Suspension Group of Input Parameters (not presently used) } \\
\hline $\begin{array}{l}\text { PDFATEs } \\
\text { Symbol }\end{array}$ & Description & Typical Value & Unit \\
\hline c1 & Ambient suspension concentration & 100. & $\mathrm{~g} / \mathrm{m}^{3}$ \\
\hline a1 & Coefficient for concentration-enhanced settling rate & 0.0002 & $\mathrm{~m} / \mathrm{sec}$ \\
\hline a2 & Concentration-enhanced settling exponent & 1.33 & 0 \\
\hline cwu & Upper limit for enhanced settling & 1500. & $\mathrm{~g} / \mathrm{m}^{3}$ \\
\hline cw1 & Lower limit for enhanced settling & 100. & $\mathrm{~g} / \mathrm{m}^{3}$ \\
\hline
\end{tabular}

\begin{tabular}{|l|l|l|l||}
\hline \multicolumn{4}{|l|}{ Table 4. Underflow Sediment Condition Group of Input Parameters } \\
\hline $\begin{array}{l}\text { PDFATEs } \\
\text { Symbol }\end{array}$ & Description & Typical Value & Unit \\
\hline \hline tau_d & Threshold for deposition $\tau_{c d}$ & 0.03 & $\mathrm{~Pa}$ \\
\hline cs & Bed density upon formation & 180. & $\mathrm{~kg} / \mathrm{m}^{3}$ \\
\hline ws1 & Reference settling rate & 0.00015. & $\mathrm{~m} / \mathrm{sec}$ \\
\hline b2 & Settling rate coefficient & 0.003 & $\mathrm{~m}^{3} / \mathrm{kg}$ \\
\hline b1 & Settling rate exponent & 5.3 & 0 \\
\hline tuy1 & Yield stress coefficient & 832. & $\mathrm{~Pa}$ \\
\hline tuy2 & Yield stress exponent & 3.0 & 0 \\
\hline mu1 & High-shear viscosity coefficient & 206. & 0 \\
\hline mu2 & High-shear viscosity exponent & 1.68 & 0 \\
\hline mu3 & Low-shear viscosity coefficient & $4.23 \mathrm{e} 4$ & 0 \\
\hline mu4 & Low-shear viscosity exponent & 2.8 & 0 \\
\hline \hline
\end{tabular}

\begin{tabular}{|l|l|l|l||}
\hline \multicolumn{4}{|l||}{ Table 5. Run Control Group of Input Parameters } \\
\hline $\begin{array}{l}\text { PDFATEs } \\
\text { Symbol }\end{array}$ & Description & Typical Value & Unit \\
\hline total_t & Total discharge time & 18.1 & hours \\
\hline x_step & Horizontal step-size & 1.0 & $\mathrm{~m}$ \\
\hline out_inc & Print-out $x$ step spacing & 2. & \\
\hline num_sweeps & Maximum number of computational sweeps & 8. & \\
\hline num_steps & The number of depths along x-axis at x-step interval & 475. & \\
\hline
\end{tabular}




\begin{tabular}{|l|l|l|l||}
\hline \multicolumn{2}{|l|}{ Table 6. Depth Input } & \\
\hline \hline PDFATEs & Description & Typical Value & Unit \\
Symbol & List of space-delimited depths of length num_steps & 1. & $\mathrm{~m}$ \\
\hline \hline$z[]$ & & 1.007 & \\
& & 1.014 & \\
\hline
\end{tabular}

The Laguna Madre example is presented here only to illustrate the operation of the PDFATEs model, and a thorough report will be made on the complete application at a later time. The Laguna Madre investigation is continuing as more information is developed in an effort to validate PDFATEm and learn more about dredge pipeline underflows in general.

At the Laguna Madre site, underflow thicknesses or heights and densities were measured while the pipeline discharge was occurring. A special push-tube sampler allowed underflow density determination with a few minutes of sampling. Samples were collected for analysis of the underflow concentration to supplement the field density measurements. Underflow particle size distribution and ambient water column suspended sediment concentrations were also measured.

Some of the important results from the field measurements were as follows: Particle segregation by deposition was indicated along the underflow. The mean underflow particle size decreased with distance from the discharge point indicating that the coarse fraction of dredged channel sediments was depositing near the discharge point. The underflow thickness was uniform and dropped off rapidly near the limit of downslope extent. The underflow had a distinct upper surface or interface with the ambient water column. The concentrations near this upper surface were uniform along the length of the underflow. This observation lead to the model feature which tends to maintain laminar underflow concentrations while deposition occurs. Field concentrations showed appreciable vertical gradation while, as described, the PDFATE model assumes the concentration to be uniform over the vertical.

Computed profiles of underflow and depositional heights are shown in Figure 5 for 6.7 and $18.8 \mathrm{hr}$ after the discharge began. The downslope extent at 18.8 hours was slightly less than at $6.9 \mathrm{hr}$ due to the deposit development and loss of slope that occurred at x distances between 110 and $190 \mathrm{~m}$. The underflow thicknesses remained generally similar with time but increased at $\mathrm{x}$ distances between 200 and $250 \mathrm{~m}$ at hour 18.8. The underflow extent in plan view is shown in Figure 6. The most rapid spreading occurred near the underflow origin, where entrainment was highest. Spreading was about constant between $\mathrm{x}$ distances of 20 to $230 \mathrm{~m}$, then decreased at greater $\mathrm{x}$ distances where the current became laminar. Because of the dependence of lateral spreading on local entrainment and flow conditions, underflow footprints are not self-similar. The variation of time, velocity, concentration, and sediment discharge along $\mathrm{x}$ are shown in Figure 7. The underflow velocity decreased rapidly near the origin, slightly increased, then decreased slowly over the remainder of the $\mathrm{x}$ extent. The underflow concentration remained about steady, then decreased until the onset of laminar flow, after which it was constant.

A TABS-MDS numerical hydrodynamic and sediment transport model has been developed that includes this pipeline disposal site and the rest of the $1,500 \mathrm{~km}^{2}$ Laguna Madre. This model has 

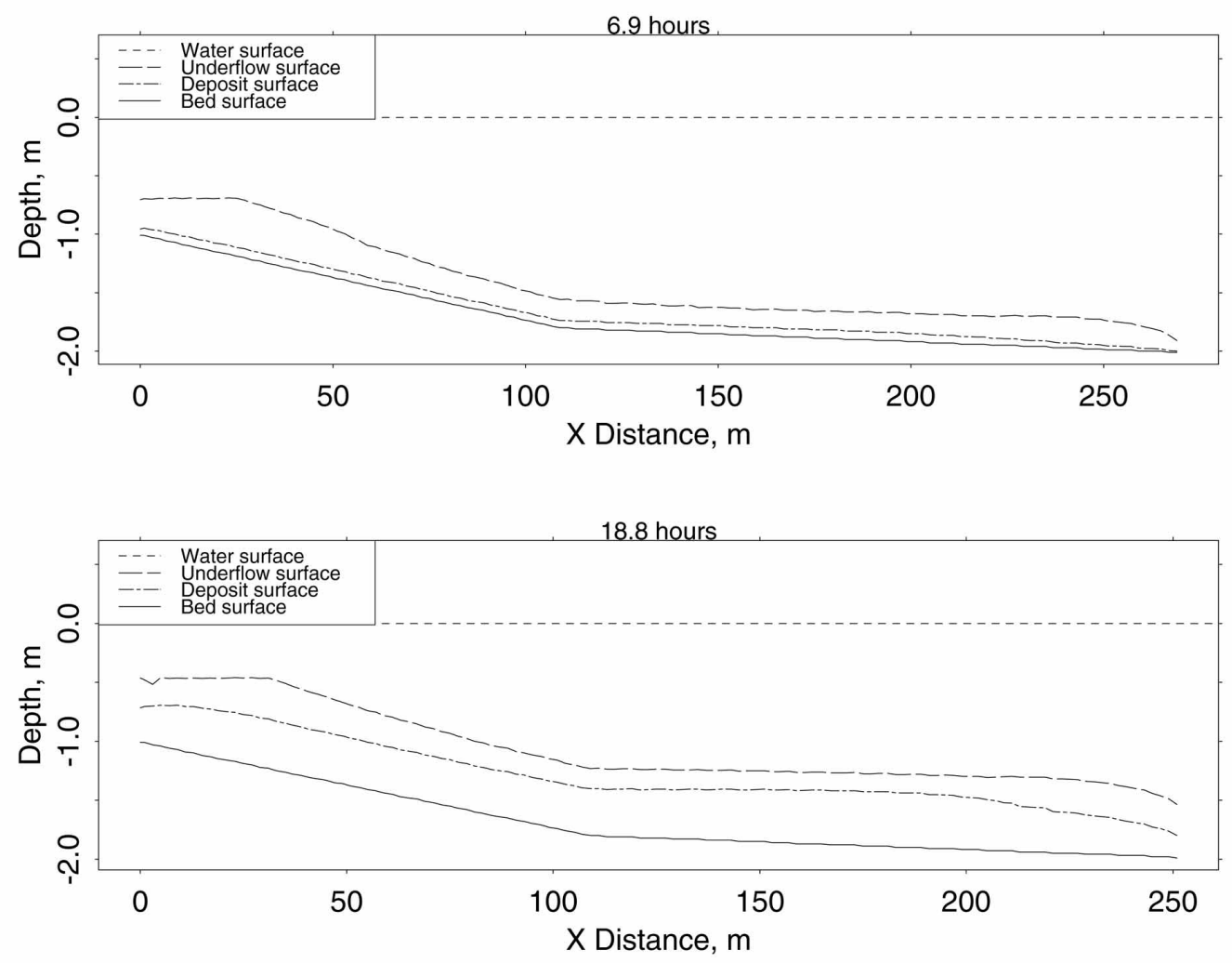

Figure 5. Computed underflow and deposit profiles at two times

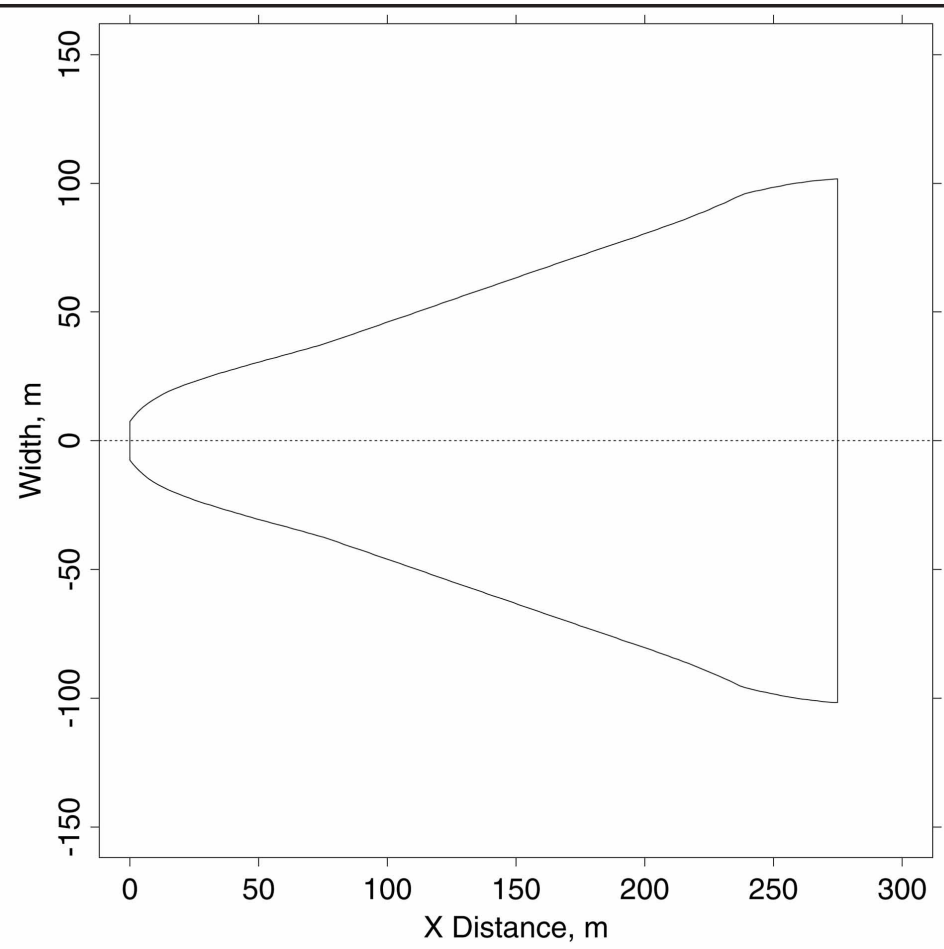

Figure 6. Plan view of computed underflow footprint showing spreading with distance along the $x$-axis 


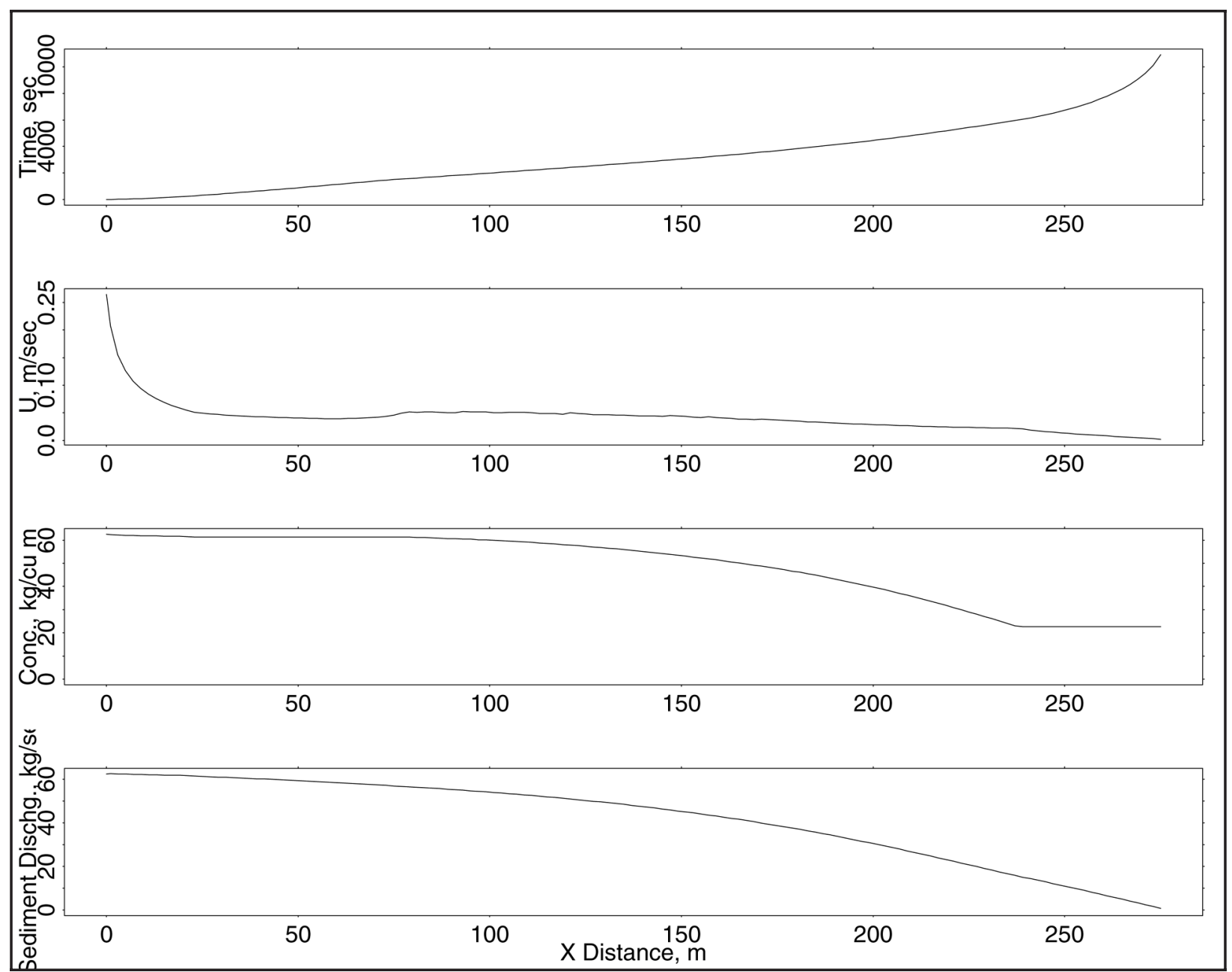

Figure 7. Computed variations of time to reach $\mathrm{x}$ distance, underflow velocity, concentration, and sediment discharge along the $\mathrm{x}$-axis

been used in a separate study of the erosion and circulation of disposed dredged material and impacts on underwater light conditions. A description of this study and some model results are located at: http://chl.wes.army.mil/research/estuaries/lagunamadre/

CONCLUSIONS: The initial results from the PDFATEs model indicate general agreement with features observed in the field. Underflow thicknesses were about the same in the model as observed in the field. The extent of the underflow could not be accurately measured in the field but appeared to be in rough agreement with the model predictions. Underflow concentrations were too high in the model, probably due to incorrect specification of the transition conditions. If the necessary input data are available, the model can be set up and run in a short amount of time. Rheological data on muds are scarce, but it remains to be determined how sensitive the model is to these parameters. Some model development work remains to verify approaches, especially with respect to the multiple grain class version of the model, and relationships incorporated into the model. Additional model validation is planned for the multiple grain class version PDFATEm using the Laguna Madre data set. 
FUTURE MODEL DEVELOPMENT: The PDFATEm is being linked to the SSFATE model that is described in Johnson et al. (2000), and should be available by summer of 2001. The underflow extent and characteristics will be input from PDFATEm into the SSFATE model framework. Possible entrainment of the underflow material by the overlying flow and the transport by currents will be computed. SSFATE transports four grain classes from clay to fine sand. The PDFATEm model will be given additional testing and comparisons when the SSFATE model becomes available, and as other application opportunities present themselves. Multiple grain class transport and water column/underflow exchange features will be completed and tested. Other model features such as arresting or overtopping flows at an underwater obstruction such as a berm and lateral limits to spreading will be considered.

POINTS OF CONTACT: For additional information, contact Mr. Allen M. Teeter (601-6342820, Allen.M.Teeter@erdc.usace.army.mil), or the Program Manager of the Dredging Operations Environmental Research Program, Dr. Robert M. Engler (601-634-3624, Robert.M.Engler@erdc. usace.army.mil). This technical note should be cited as follows:

Teeter, A. M. (2000). "Simulating underflow spreading from a shallow-water pipeline disposal," DOER Technical Notes Collection (ERDC TN-DOER-N11), U.S. Army Engineer Research and Development Center, Vicksburg, MS. www.wes.army.mil/el/dots/doer

\section{REFERENCES}

Bonnecaze, R. T., and Lister, J. R. (1999). "Particle-driven gravity currents down planar slopes," Journal of Fluid Mechanics 390,75-91.

Fang, X., and Stefan, H. G. (1998). "Dependence of dilution of a plunging discharge over a sloping bottom on inflow conditions and bottom friction," J. Hydraulics Res. 38(1), 15-25

Findikakis, A. N., and Law, A. W. K. (1998). "Marine tailings disposal simulation," Journal of Hydraulic Engineering 124(4), 370-383.

Garcia, M. H. (1994). "Depositional turbidity currents laden with poorly sorted sediment," Journal of Hydraulic Engineering 120(11), 1240-1263.

Johnson, B. H., Anderson, E., Isaji, T., and Clarke, D. G. (2000). "Description of the SSFATE numerical modeling system," Doer Technical Notes Collection (ERDC TN-DOER-E10), U.S. Army Engineer Research and Development Center, Vicksburg, MS. www.wes.army.mil/el/dots/doer

Kranenburg, C., and Winterwerp, J. (1997). "Erosion of fluid mud layers, Part I: Entrainment model," Journal of Hydraulic Engineering 123(6), 504-511.

Teeter, A. M. (2000). “Underflow spreading from an open-pipeline disposal,” Doer Technical Notes Collection (ERDC TN-DOER-N7), U.S. Army Engineer Research and Development Center, Vicksburg, MS. www.wes.army.mil/el/dots/doer

Van Kessel, T., and Kranenburg, C. (1996). "Gravity current of fluid mud on sloping bed," Journal of Hydraulic Engineering 122(12), 710-717.

NOTE: The contents of this technical note are not to be used for advertising, publication, or promotional purposes. Citation of trade names does not constitute an official endorsement or approval of the use of such products. 